\title{
Congenital absence of uterine cervix
}

\author{
Selvaraj Ravi Lakshmy*, Nity Rose
}

Shri Lakshmi Scan Centre, 185/386-A, Govindhachetty Street, NCR Complex, Kaveripattinam 635112, Krishnagiri, Tamilnadu, India

Received: 15 August 2016

Accepted: 12 September 2016

\author{
*Correspondence: \\ Dr. Selvaraj Ravi Lakshmy, \\ E-mail: drlakshmiravi@gmail.com
}

Copyright: (c) the author(s), publisher and licensee Medip Academy. This is an open-access article distributed under the terms of the Creative Commons Attribution Non-Commercial License, which permits unrestricted non-commercial use, distribution, and reproduction in any medium, provided the original work is properly cited.

\begin{abstract}
Cervical agenesis or dysgenesis is an extremely rare congenital anomaly. Patients with congenital absence of the cervix present with primary amenorrhea and infertility. Though it poses a diagnostic challenge to the clinician, correct diagnosis prior to surgery is possible with the help of ultrasound. Early diagnosis offers significant advantages in patient care and effective presurgical planning. This case report reviews two cases of cervical agenesis diagnosed with the help of ultrasound and later confirmed with the help of MRI. Ultrasonography is the modality of choice to define the internal genital anatomy and helps us to classify the level of obstruction or aplasia in obstructive uterine anomalies.
\end{abstract}

Keywords: Cervical agenesis, Dysgenesis, Congenital anomaly, Primary amenorrhea, Infertility, Ultrasonography

\section{INTRODUCTION}

Cervical agenesis or dysgenesis is an extremely rare congenital anomaly with an occurrence of about 1 in 80,000 to 100,000 births. ${ }^{1}$ It may be isolated or associated with partial or complete agenesis of vagina. ${ }^{2}$ The review of literature lists less than 200 reported cases since $1900 .^{3}$ Diagnosis of cervical atresia is a difficult entity but the possibility of making a correct diagnosis prior to surgery do exists with the help of ultrasound. Early diagnosis offers significant advantages in patient care, the most important of which is effective presurgical planning and preparation. ${ }^{2,4}$ We report two cases of cervical atresia diagnosed using ultrasound which were later confirmed with MRI.

\section{CASE REPORT}

A 26 year old woman presented for evaluation with infertility and primary amenorrhea. She had complaints of vague lower abdominal pain and had been treated at various centres for the past ten years for primary amenorrhea. She presented with a history of failed attempted reconstructive pelvic surgery two years before. Her secondary sexual characters were normal and on pelvic examination a blind short vaginal pouch was found and the cervix could not be visualized on per speculum examination.

Transabdominal pelvic ultrasound revealed the uterus with inadequate visualization of the cervix. (Figure 1a, 1b). Both ovaries and adnexa appeared normal. Transvaginal examination shows the tapering cervix (Figure 1c) with adenomyotic changes and ill-defined endometrium (Figure 1d). Figure 1e demonstrates the blind ending noncanalised cervix with minimal fluid in pelvis. Figure $1 \mathrm{f}$ is the three dimensional rendered image of the cervix.

The next case is a 23year old presenting for evaluation of infertility, primary amenorrhea and lower abdominal pain. Her previous ultrasound reports done elsewhere revealed normal appearance of uterus and ovaries. She had well developed secondary sexual characters with no urinary or bowel complaints and her history was not suggestive of any familial or endocrinological disorder. 
Figure $2 \mathrm{a}$ is an illustration of transabdominal pelvic ultrasound which reveals the fundus of uterus but the cervical region appears ill-defined. Transvaginal sonography revealed the noncanalised cord like structure measuring about $9 \mathrm{~mm}$ in its anteroposterior dimension, extending downwards from the uterine corpus (Figure 2b). Three dimensional rendering of uterus is illustrated in Figure 2c. The MRI findings in both cases correlated with the depicted sonographic anatomy. No renal anomalies were found in both cases.

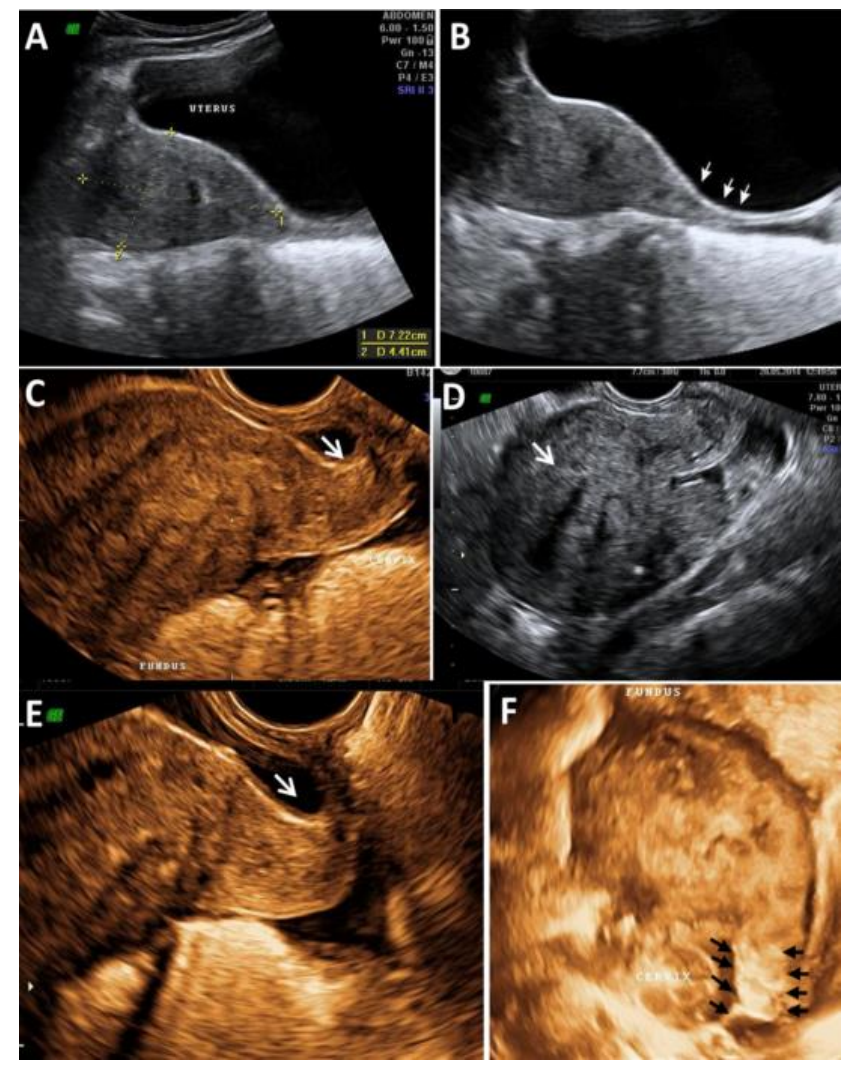

Figure 1: Ultrasound images; A, B - Transabdominal scan showing longitudinal section of uterus with inadequate visualization of cervix (b - Arrows point to region of cervix) $\mathrm{C}$ - Transvaginal scan showing the tapering noncanalised cervix. D - Transvaginal scan depicting adenomyotic changes in uterine corpus. $\mathrm{E}$ Blind ending noncanalised cervix with free fluid seen in pelvis. F- 3D rendered image of blind ending cervix.

\section{DISCUSSION}

Obstructive uterine anomalies occlude the normal menstrual flow resulting in primary amenorrhea. Any abdominal or pelvic pain in a pubescent girl must evoke the suspicion of possible obstructive genital anomaly. Clinically it may present with obstructive symptoms like hematometra, hematocolpos, cyclical lower abdominal pain, or may be asymptomatic depending on the functional status of the endometrium ${ }^{5}$. Endometriosis can develop from retrograde menstruation in such cases. ${ }^{6}$ Clinical examination helps in identifying lower genital tract anomalies like imperforate hymen or blind vaginal pouch but the distinction between cervical atresia and a high vaginal transverse septum is not possible. ${ }^{5}$

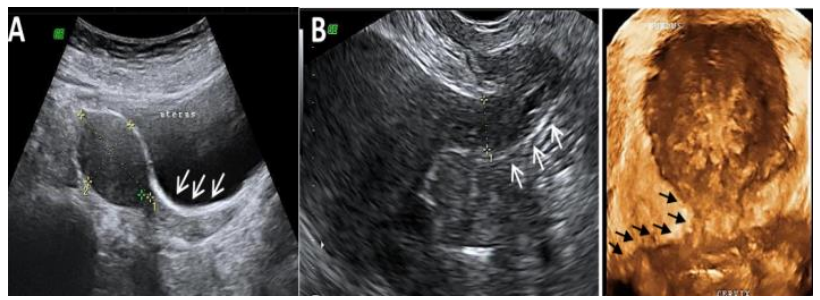

Figure 2: Ultrasound images; A - Transabdominal scan - Longitudinal section of uterus with inadequately visualized cervix. Uterine corpus measures $4.3 \times 2.8 \mathrm{cms}$. B - Transvaginal scan - Cervix replaced by fibrous cord measuring $0.9 \mathrm{~cm}$ in its anteroposterior dimension. C - 3D rendered image depicting the cord like cervix.

Patients with cervical aplasia and a functioning midline uterine corpus may have aplasia of the lower two thirds of the vagina with an upper vaginal pouch. Similarly, some patients have a considerable atretic segment of vagina and an upper vaginal pouch with a poorly developed uterine cervix and corpus above. Differentiation of these two mullerian anomalies is essential. With cervical dysgenesis, there is no vaginal dilatation from the accumulation of blood, as seen with a high transverse vaginal septum. Imaging modalities like ultrasound and MRI are most helpful when they are correlated with the findings of a careful pelvic examination.

Primary amenorrhea can be the presenting symptom for a broad spectrum of congenital uterine anomalies ranging from hypoplastic uterus to imperforate hymen. Ultrasonography is the modality of choice to define the internal genital anatomy and helps us to classify the level of obstruction or aplasia., ${ }^{7,8}$ The initial suspicion of cervical agenesis or dysgenesis can be easily done with ultrasonography in spite of its rare occurrence. Three dimensional ultrasound further improves our ability to accurately describe cervical anatomy though it requires operator expertise and adequate knowledge about the anatomical types. ${ }^{9}$ In both our cases, we used three dimensional ultrasound to define the cervical anatomy precisely.

According to the American Society of Reproductive Medicine (formerly American Fertility Society), cervical agenesis is classified as type Ib Mullerian anomaly. ${ }^{10}$ Cervical atresia has been further classified into different types as follows ${ }^{5,11-13}$ (i) The cervical body is intact with obstruction of the cervical os (ii) The cervical body consists of a fibrous band (iii) Fragmented portions of the cervix are noted (iv) The midportion of the cervix is hypoplastic with a bulbous tip. Imaging modalities should assess the nature of cervical remnant precisely as the reconstructive surgery is based on the anatomy observed. So far, MRI has been considered as a consistently 
superior method for evaluating the vaginal and cervical anatomy but recently three dimensional ultrasound has gained importance. ${ }^{14}$

The goals of reconstructive surgery are to provide a conduit for menstruation, to relieve pain and to preserve reproductive potential. Patients with atresia or cervical fragmentation are usually poor candidates for canalization and total hysterectomy is the treatment of choice. ${ }^{15}$ Patients with either cervical obstruction or a fibrous cord may reasonably be considered for reconstruction. ${ }^{5,12}$ Controversies do exist in the treatment options and some authors describe uterovaginal anastomosis as the first line of management. ${ }^{16,17}$ However a complete preoperative evaluation is essential to provide useful information about the remnant cervix which serves as the basis for assessing the risks and benefits of the possible procedures to be performed. Patient consent was obtained prior to the study and patient identity not disclosed.

\section{CONCLUSION}

Patients with congenital absence of the cervix present a diagnostic challenge. It is a complex surgical problem and should be dealt with a thorough evaluation. Routine ultrasound evaluation can diagnose this condition and can provide relevant information on the cervical anatomy. Careful evaluation of the cervix is essential in primary amenorrhea and the possibility of cervical atresia should be considered.

\section{Funding: No funding sources}

Conflict of interest: None declared

Ethical approval: The study was approved by the Institutional Ethics Committee

\section{REFERENCES}

1. Suganuma N, Furuhashi M, Moriwaki T, Tsukahara $\mathrm{S}$, Ando $\mathrm{T}$, Ishihara Y. Management of missed abortion in a patient with congenital cervical atresia. Fertil Steril. 2002;77:1071-3.

2. Markham SM, Parmley TH, Murphy AA, Huggins GR, Rock JA. Cervical agenesis combined with vaginal agenesis diagnosed by magnetic resonance imaging. Fertility and sterility. 1987;48(1):143-5.

3. Grimbizis GF, Tsalikis T, Mikos T, Papadopoulos N, Tarlatzis BC, Bontis J. Successful end to end cervicocervical anastomosis in a patient with congenital cervical fragmentation: case report. Hum Reprod. 2004;5:1204-10.

4. Valdes C, Malini S, Malinak LR. Sonography in the surgical management of vaginal and cervical atresia. Fertility and sterility. 1983;40(2):263-5.
5. Deffarges JV, Haddad B, Musset R, Paniel BJ. Utero-vaginal anastomosis in women with uterine cervix atresia: Long-term follow-up and reproductive performance. A study of 18 cases. Hum Reprod. 2001;16:1722-5.

6. Olive DL, Henderson DY. Endometriosis and mullerian anomalies. Obstetrics Gynecology. 1987;69(3):412-5.

7. Blask AR, Sanders RC, Gearhart JP. Obstructed uterovaginal anomalies: demonstration with sonography. Part I. Neonates and infants. Radiology. 1991;179(1):79-83.

8. Sherer DM, Beyth Y. Ultrasonographic diagnosis and assisted surgical management of hematotrachelos and hematometra due to uterine cervical atresia with associated vaginal agenesis. Journal of ultrasound in medicine: official journal of the American Institute of Ultrasound in Medicine. 1989;8(6):321.

9. Woelfer B, Salim R, Banerjee S, Elson J, Regan L, Jurkovic D. Repro-ductive outcomes in women with congenital uterine anomalies detectedby threedimensional ultrasound screening. Obstet Gynecol. 2001;98:1099-103.

10. The American Fertility Society. The American Fertility Society classifications of adnexal adhesions, distal tubal occlusion, tubal occlusion secondary to tubal ligation, tubal pregnancies, Mullerian anomalies and intrauterine adhesions. Fertil Steril. 1988;49:944-55.

11. Buttram VC, Gibbons WE: Mullerian anomalies: a proposed classification (an analysis of 144 cases). Fertil Steril. 1979;32:40-6.

12. Xie Z, Zhang X, Liu J, Zhang N, Xiao H, Liu Y. Clinical characteristics of congenital cervical atresia based on anatomy and ultrasound: a retrospective study of 32 cases. Europ jour of medi rese. 2014;19(1): 1 .

13. Rock JA, Schlaff WD, Zacur HA, Jones HW Jr. The clinical management of congenital absence of the uterine cervix. Int J Gynaecol Obstet. 1984;22:231-5.

14. Vallerie AM, Breech LL. Update in Müllerian anomalies: diagnosis, management, and outcomes. Current Opinion in Obstetrics and Gynecology. 2010;22(5):381-7.

15. Acién P, Acién M, Ferrer MS. Complex malformations of the female genital tract. New types and revision of classification. Hum Reprod. 2004; 19:2377-84.

16. Farber M, Marchant DJ. Congenital absence of the uterine cervix. American journal of obstetrics and gynecology. 1975;121(3):414-7.

17. Creighton SM, Davies MC, Cutner A. Laparoscopic management of cervical agenesis. Fertil Steril. 2006;85:1510.e13-5.

Cite this article as: Lakshmy SR, Rose N.

Congenital absence of uterine cervix. Int J Reprod

Contracept Obstet Gynecol 2016;5:3634-6. 